\title{
Motivação e clima organizacional: um estudo de caso em uma Instituição Pública Federal de Ensino Superior do DF*
}

\author{
Motivation and organizational climate: \\ a case study in a Federal Public Institution of \\ Higher Education of the Federal District
}

Patrícia Lira Barros ${ }^{1}$

José Airton Mendonça de Melo²
Recebido em: 02/10/2015.

Aprovado em: 24/02/2016.

1 Patrícia Lira Barros: Bacharel em Administração, graduada pela Faculdade Projeção, unidade Sobradinho - DF. Formada em julho de 2015. E-mail: pat.lb@hotmail.com.

2 Jose Airton Mendonça de Melo: Doutor em Economia pela Universidade Federal do Ceará, técnico do Banco do Nordeste, Professor da Faculdade Projeção. E-mail: jose.melo@ projecao.br.

\section{Resumo}

Esse trabalho tem como objetivo pesquisar a influência do clima organizacional na motivação dos colaboradores de um dos setores de uma Instituição Pública Federal de Ensino Superior do Distrito Federal. Trata-se de uma pesquisa de natureza descritiva, cujas técnicas de coleta de dados compreendem um levantamento bibliográfico e uma pesquisa de campo em uma organização pública do segmento educacional, com vistas a entender como determinados elementos do clima da organização podem influenciar a motivação dos colaboradores inseridos no contexto da instituição. Os achados mais importantes do estudo são os resultados positivos dos fatores que mensuram o clima, dentre eles a clareza organizacional, reconhecimento, condições físicas e materiais, trabalho em equipe, relacionamento interpessoal, conflitos, rotatividade, produtividade, liderança e avaliação de desempenho, e ainda a relação afirmativa da influência do clima na motivação dos colaboradores.

Palavras-chave: Gestão de pessoas. Motivação. Clima organizacional.

\begin{abstract}
This study aims to explore the influence of organizational climate on employee motivation in one of the sectors of a Federal Public Institution of Higher Education of the Federal District. A descriptive research, whose data collection techniques include a literature review and field research in a public organization of the educational sector, in order to understand how certain organizational elements can influence the motivation of employees within the context of the institution. The most important findings of the study are the positive results of the factors that measure the organizational climate, including the organizational clarity, recognition, physical and material conditions, teamwork, interpersonal relationships, conflicts, turnover, productivity, leadership and performance evaluation as well affirmative relationship of climate influence on employee motivation.
\end{abstract}

Keywords: People management. Motivation. Organizational climate. 


\section{Introdução}

O clima organizacional é um elemento extremamente importante no contexto de uma organização. $\mathrm{O}$ clima adequado no ambiente de trabalho se tornou um fator relevante na satisfação dos colaboradores, pois estes passam grande parte do seu tempo dentro da empresa. Sendo o clima benéfico, pode haver influência positiva na motivação, entretanto, se o clima é desfavorável, pode haver frustração e, consequentemente, desmotivação para a realização das atividades e a constante motivação dos colaboradores é um aspecto significativo e fundamental para o sucesso organizacional.

A pesquisa de satisfação interna é uma ferramenta cada vez mais utilizada por empresas que prezam pelo bem-estar de seus colaboradores e tem sido aplicada nos mais diversos tipos de organizações, objetivando mensurar o grau de qualidade do clima organizacional. Nota-se, atualmente, a importância do capital humano, por isso, é imprescindível que o ambiente em que os colaboradores estão inseridos tenha um clima de fato benéfico, até mesmo por questões relacionadas à saúde, para, assim, evitar o aparecimento de possíveis doenças ocupacionais de cunho psicológico, por exemplo a depressão, que é um grande mal para sociedade contemporânea.

O tema proposto pode contribuir na melhoria da performance da organização, uma vez que, ao se compreender o clima da empresa e sua real importância no fator motivacional dos colaboradores, pode-se otimizar o ambiente de trabalho, tornando-o produtivo e possibilitando resultados efetivos para a organização. Segundo Chiavenato (2005, p. 52) “o clima organizacional influencia a motivação, o desempenho humano e a satisfação no trabalho". A temática ainda se justifica pela abrangência na literatura, em que a importância do assunto é reconhecida, tanto em relação ao clima organizacional quanto ao estudo da motivação, sendo estes abordados em diversas publicações científicas.

A pesquisa desenvolvida é de natureza descritiva e tem como técnica de coleta de dados o levantamento bibliográfico e a pesquisa de campo.

O objetivo geral do estudo consiste em pesquisar a influência do clima organizacional na motivação dos colaboradores do setor da instituição analisada, considerando os seguintes objetivos específicos: I) levantar a fundamentação teórica que responda e fundamente uma resposta ao problema levantado no estudo; II) identificar e conceituar os métodos de pesquisa, o público-alvo a ser pesquisado e as técnicas de coleta de dados mais adequadas ao objetivo do estudo; III) detectar os principais fatores no clima organizacional que influenciam na motivação dos colaboradores do setor da empresa estudada; e IV) desenvolver um diagnóstico sobre a situação do estudo de caso.

Para atender a esses objetivos, a pesquisa está estruturada em quatro seções, além desta Introdução. A primeira compreende a revisão teórica, que aborda aspectos do clima organizacional e as principais teorias sobre motivação. A segunda trata da metodologia da pesquisa. A terceira seção contempla a análise, que faz uma descrição e discussão analítica dos dados e informações levantadas no desenvolvimento da pesquisa. Na última, são apresentadas as conclusões finais do estudo.

\section{Revisão teórica}

Este capítulo apresenta a fundamentação teórica sobre os assuntos centrais desta pesquisa: o clima organizacional e a motivação. O objetivo é justificar, por meio de referências bibliográficas, a conceituação e a relação dessas duas variáveis e fundamentar os elementos interligados a esses assuntos.

\subsection{Clima organizacional}

Litwin (apud LUZ, 2005, p. 10) conceitua o clima organizacional como sendo a qualidade ou propriedade do ambiente organizacional, que é percebida ou experimentada pelos membros da organização e influencia o seu comportamento.

Para Luz (2005, p. 12), “clima organizacional é o reflexo do estado de ânimo ou do grau de satisfação dos funcionários de uma empresa, num dado momento".

Segundo Chiavenato (2005, p. 52), o termo clima organizacional se refere aos aspectos internos de uma organização, à atmosfera psicológica e às características da empresa, ele pode ser sentido psicologicamente e está relacionado especificamente às propriedades motivacionais do ambiente interno da organização. O clima compõe a qualidade do ambiente da empresa, sendo percebido pelos colaboradores da organização e influenciando diretamente o comportamento dos mesmos. $\mathrm{O}$ autor ainda ressalta a influência do clima na motivação:

O clima organizacional influencia a motivação, o desempenho humano e a satisfação no traba- 
lho. Ele cria certos tipos de expectativas sobre as quais consequências se seguem em decorrência de diferentes ações. As pessoas esperam certas recompensas, satisfações e frustrações na base de suas percepções do clima organizacional. Essas expectativas - quando positivas - tendem a aumentar a motivação das pessoas (CHIAVENATO, 2005, p.).

Souza (apud GRAÇA, 1999, p. 9) diz que "o clima é uma resultante das variáveis culturais, assim entendida como a soma dos valores, costumes, tradições, e propósitos que fazem com que uma empresa seja singular". O autor acredita que, quando essas variáveis são alteradas, ocasionam alterações no clima, e isso é mais perceptível do que suas fontes causais.

Litwin e Stringer (apud GRAÇA, 1999, p. 10) identificaram sete variáveis-chave no clima organizacional, as quais definiram como suas dimensões: conformismo com a estrutura da empresa; responsabilidade pessoal; padrões de desempenho; recompensas; clareza organizacional; liderança; apoio e calor humano.

O clima organizacional deve ser medido, sendo de extrema importância a sua avaliação. Luz (2005, p. 22) acredita que as organizações devem ouvir seus colaboradores por meio da área de Recursos Humanos, pois faz parte de sua missão proporciona-lhes um clima organizacional favorável. Esse objetivo de tornar a mão de obra satisfeita ou "motivada" está contido na literatura técnica quanto ao cotidiano da Administração de Recursos Humanos. Logo, se "motivar" ou ao menos tornar satisfeitos os funcionários é parte da missão da gestão de pessoas, então ela deve diagnosticar, periodicamente, o clima da empresa com o objetivo de saber se está de fato cumprindo sua missão:

A Administração de Recursos Humanos ou do Ativo Humano, como querem alguns, busca, entre outros objetivos, alcançar a satisfação e a "motivação" dos colaboradores da organização. Ela deve procurar o pleno aproveitamento desses recursos, dispondo-os para que ofereçam um maior rendimento organizacional, expresso em termos de efetividade e produtividade, com o melhor nível de realização individual, expresso em termos de satisfação pessoal e geral. Para isso, ela precisa diagnosticar, periodicamente o clima organizacional, com o objetivo de saber se a parte mais nobre de sua missão está sendo atingida (GRAÇA, 1999, p. 23).

Para Graça (1999), quando o administrador compreende o conceito de clima organizacional, pode manejar a motivação de seus colaboradores, aumentando a eficiência de sua equipe de colaboradores.
Luz (2005, p. 13) relata que podemos encontrar pelo menos três palavras-chave relacionadas ao conceito de clima organizacional: satisfação (dos funcionários), percepção (dos funcionários) e cultura (da organização).

O clima organizacional é, de certa forma, o reflexo da cultura da organização, ou melhor, o reflexo dos efeitos dessa cultura, na organização como um todo. Luz (1995) afirma que o "clima é resultante da cultura das organizações; de seus aspectos positivos e negativos (conflitos)".

\subsubsection{Indicadores do Clima Organizacional}

Conforme Luz (2005, p. 32), embora o clima seja de fato abstrato, ele se materializa nas empresas sinalizando sobre a sua real qualidade por meio de alguns indicadores:

Turnover: conhecido como a rotatividade de pessoal, quando elevado, demonstra falta de comprometimento por parte dos colaboradores e pode ser um sinal de que a empresa não satisfaz adequadamente os funcionários;

Absenteísmo: faltas frequentes dos colaboradores pode também ser ocasionado por insatisfação com o ambiente de trabalho;

Avaliação de desempenho: o baixo desempenho de determinados colaboradores decorre de seu estado de ânimo, de sua apatia em relação à empresa, ou até mesmo por problemas pessoais. Ressalta-se a importância dos gestores em ouvir seus colaboradores;

Greves: embora as greves estejam mais vinculadas ao descumprimento de obrigações legais por parte das empresas, a adesão por parte dos colaboradores revela uma reação ao seu descontentamento com a empresa;

Conflitos interpessoais e interdepartamentais: essa é a forma mais aparente do clima de uma organização, a intensidade dos conflitos é o que vai determinar, muitas vezes, se o clima é tenso ou agradável;

Desperdício de material: forma velada do trabalhador se rebelar contra as condições de trabalho a que está sujeito;

Queixas no serviço médico: alguns colaboradores fazem uso dos consultórios médicos das empresas para fazer reclamações sobre suas angustias em relação ao trabalho, como: sobrecarga, humilhações, constrangimentos, exposição a situações vexatórias, discriminações etc. Muitos desses problemas transformam-se em distúrbios emocionais, que acabam gerando doenças e influindo negativamente na qualidade de vida dos empregados. 


\subsection{Cultura organizacional}

De acordo com Moura (apud LUZ, 2005, p. 15), a cultura de uma organização é um conjunto de valores, normas e princípios, já estabelecidos na vida organizacional e que interage com a estrutura e os comportamentos, provocando uma forma própria de como proceder naquela empresa, baseado em certos fundamentos com o objetivo de obter determinados resultados.

Para Wagner e Hollenbeck (2004, p. 367), a cultura organizacional é uma maneira informal e compartilhada de perceber a vida e a participação na empresa, preservando os seus membros unidos e influenciando o que pensam sobre si mesmos e seu trabalho. Ela é composta por vários elementos, a saber:

- Cerimônias: eventos especiais nos quais os membros da organização celebram os mitos, heróis e símbolos da empresa;

- Ritos: atividades cerimoniais destinadas a comunicar ideias específicas ou a realizar determinados propósitos;

- Rituais: ações regularmente repetidas para reforçar normas e valores culturais;

- Histórias: relatos de eventos passados que ilustram e transmitem normas e valores culturais mais profundos;

- Mitos: histórias imaginárias que ajudam a explicar atividades ou eventos que de outro modo poderiam ser confusos;

- Heróis: pessoas de sucesso que corporificam os valores e o carácter da organização e de sua cultura;

- Símbolos: objetos, ações ou eventos dotados de significados especiais e que permitem aos membros da organização trocarem ideias complexas e mensagens emocionais;

- Linguagem: conjunto de símbolos verbais que geralmente reflete a cultura particular da organização.

Todas as organizações apresentam uma cultura organizacional que se caracteriza pelos valores que esposam, pela regularidade de comportamento de seus membros, pela filosofia que guia suas políticas e pelo clima expresso tanto por seu layout físico quanto pela interação de seus membros entre si e com o público externo (GIL, 2014, p. 42).

A cultura organizacional é um padrão de assuntos básicos compartilhados, que um grupo aprendeu como maneira de resolver seus problemas de adaptação externa e de integração interna e que funciona bem a ponto de ser considerado válido e desejável para ser transmitido aos novos membros como forma correta de perceber, pensar e sentir em relação aos seus problemas (SCHEIN, 1992 apud CHIAVENATO, 2005, p. 37).

Chiavenato (2005, p. 38) acredita que a cultura organizacional constitui a maneira pela qual cada organização aprendeu a lidar com seu ambiente. É uma complexa mistura de pressuposições, crenças, comportamentos, histórias, mitos, metáforas e outras ideias que, consideradas juntas, representam a maneira particular de uma organização funcionar e trabalhar.

Embora a cultura organizacional tenha certos pontos de intersecção com a satisfação no trabalho, ela pode ser caracterizada como um termo descritivo, se referindo à forma pela qual os funcionários percebem as características da cultura da empresa, já a satisfação se distingue como um termo avaliatório, pois se refere à maneira como os colaboradores se sentem em relação às expectativas da organização, às práticas de recompensas e outros aspectos (ROBBINS, 2002, p. 499).

A cultura Organizacional influencia o comportamento de todos os indivíduos e grupos dentro da organização. Ela impacta o cotidiano da empresa: suas decisões, as atribuições de seus funcionários, as formas de recompensas e punições, as formas de relacionamento com seus parceiros comerciais, seu mobiliário, o estilo de liderança adotado, o processo de comunicação, a forma como seus funcionários se vestem e se portam no ambiente de trabalho, seu padrão arquitetônico, sua propaganda, e assim por diante (LUZ, 2005).

\subsubsection{Relação entre clima e cultura organizacionais}

De acordo com Luz (2005, p. 20), existe uma relação de causalidade entre clima e cultura organizacionais, onde se pode afirmar que a cultura é a causa e o clima a consequência. $\mathrm{O}$ clima pode ser caracterizado como fenômeno temporal, referindo-se ao estado de ânimo dos colaboradores de uma organização em um dado momento, enquanto a cultura decorre de práticas recorrentes, estabelecidas ao logo do tempo. Além disso, o clima e a cultura são fenômenos intangíveis, pode-se inferir através dos conceitos de alguns autores que o clima e a cultura se complementam. O clima organizacional é de certa forma, o reflexo da cultura da organização, ou melhor, o reflexo dos efeitos dessa cultura, na organização como um todo. O autor ainda afirma que o "clima é resultante da cultura 
das organizações; de seus aspectos positivos e negativos (conflitos)".

\subsection{Satisfação no trabalho}

Robbins (2002) define o termo satisfação com o trabalho como a atitude geral de uma pessoa em relação ao trabalho que realiza, onde o colaborador pode ter um alto nível de satisfação e apresentar atitudes positivas como também pode ter insatisfação e apresentar o oposto, atitudes negativas. Isso significa que a avaliação que um funcionário faz de sua satisfação ou insatisfação com o trabalho é resultado de um complexo somatório de diferentes elementos, a saber: convivência com colegas e superiores; obediência a regras e políticas organizacionais; alcance de padrões de desempenho e a aceitação de condições de trabalho, geralmente abaixo do ideal. $\mathrm{O}$ autor discorre sobre a importância de se ter colaboradores satisfeitos:

Funcionários satisfeitos parecem mais propensos a falar bem da organização, ajudar os demais e ultrapassar as expectativas em relação ao seu trabalho. Além disso, funcionários satisfeitos podem estar mais dispostos a ir além de suas atribuições regulares, por querer repetir experiências positivas (ROBBINS, 2002, p. 78).

\subsubsection{Satisfação no trabalho e sua relação com o de- sempenho funcional}

Robbins (2002, p. 75) apresenta a satisfação no trabalho e o desempenho dos funcionários relacionados à produtividade, ao absenteísmo e a rotatividade:

- Satisfação e produtividade: pode-se afirmar em decorrência de pesquisas realizadas (em organizações como um todo e não somente no nível individual) que as empresas felizes são mais produtivas, pois foi identificado que funcionários satisfeitos tendem a ser mais eficazes;

- Satisfação e absenteísmo: estudos mostram que funcionários satisfeitos mesmo com possibilidade de falta (como por exemplo em decorrência de fenômenos naturais) apontam que os colaboradores que se consideravam satisfeitos têm um maior índice de comparecimento em relação aos considerados insatisfeitos, revelando que a satisfação está negativamente correlacionada ao absenteísmo;

- Satisfação e rotatividade: um importante moderador da relação satisfação e rotatividade é o nível de desempenho do trabalhador, qualquer que seja o nível de satisfação, os funcionários de melhor desempenho tendem a permanecer por um período maior na organização, porque recebem reconhecimento, elogios e outras recompensas que os levam a ter vontade de permanecer no emprego, demonstrando que a satisfação também está negativamente correlacionada com a rotatividade.

\subsection{Motivação}

A motivação pode ser definida como o processo responsável pela intensidade, direção e persistência dos esforços de uma pessoa para o alcance de uma determinada meta (ROBBINS, 2002, p. 151).

Segundo Chiavenato (2005, p. 215), “a motivação existe dentro das pessoas e se dinamiza com as necessidades humanas". Chiavenato acredita que a motivação é uma função gerencial:

$\mathrm{Na}$ realidade, a motivação está contida dentro das próprias pessoas e pode ser amplamente influenciada por fontes externas ao indivíduo ou pelo seu próprio trabalho na empresa. A motivação intrínseca e extrínseca devem se complementar por meio do trabalho gerencial. Ambas não podem ser deixadas ao acaso, simplesmente à mercê dos acontecimentos. Elas podem e devem ser perfeitamente compreendidas pelo gerente e utilizadas como ponto de apoio para potencializar e alavancar a satisfação das pessoas. O gerente deve conhecer o potencial interno de motivação de cada pessoa e deve saber extrair do ambiente de trabalho as condições externas para elevar a satisfação profissional (CHIAVENATO, 2005, p. 215).

De Acordo com Graça (1999), “a motivação de uma pessoa depende da força de seus motivos. Os motivos são, às vezes, definidos como necessidades, desejos ou impulsos, no interior do indivíduo, os motivos são dirigidos para objetivos, e estes podem ser conscientes ou inconscientes”. Para Gil (2014, p. 202) “motivação é a força que estimula as pessoas a agir".

Conforme Vergara (2011, p. 42), a motivação é uma força, uma energia que impulsiona os indivíduos na direção de algo, sendo absolutamente intrínseca, nascendo de nossas necessidades interiores. A autora discorre sobre a automotivação:

Porque a motivação é intrínseca, quando autores de determinados best-sellers falam em automotivação, estão cometendo um pleonasmo, uma redundância, um equívoco. A palavrinha auto está sobrando. Porque a motivação é intrínseca, também não podemos dizer que motivamos os outros a isso ou aquilo. Ninguém motiva ninguém. Nós é que nos motivamos, ou 
não. Tudo os que os de fora podem fazer é estimular, incentivar, provocar nossa motivação. Dito de outra maneira, a diferença entre motivação e estímulo é que a primeira está dentro de nós e o segundo, fora (VERGARA, 2011, p. 421).

De acordo com Bergamini (2011, p. 142), muitos autores confundem o termo motivação com o que na verdade se caracteriza como condicionamento ou movimento. Como exemplo, a autora discorre sobre o comportamento que é recompensado por qualquer evento externo, nele, o indivíduo tenderá naturalmente a repeti-lo. Se o comportamento for punido, tenderá a desaparecer. No caso de não haver nem recompensa, tampouco punição, a pessoa não se comportará de forma alguma por iniciativa própria. Portanto, à medida que um comportamento esteja condicionado a variáveis externas ao indivíduo não se pode concluir pela existência de uma motivação real, tratando-se de movimento condicionado por fatores extrínsecos.

Para Vergara (2011, p. 66), os indivíduos são diferentes e suas motivações também. Alguns se sentem motivados por fatores econômico-financeiros e todas as vantagens de aquisições de bens e serviços. Se o trabalho lhes proporciona benefícios dessa ordem, é possível que nele encontre significado. Outros se sentem predominantemente motivados pelo desejo de sentir-se competente, reconhecido, de participar das decisões, de realizar tarefas intrinsecamente desafiadoras e instigadoras. Se o trabalho lhes proporciona benefícios dessa ordem, é possível encontrar significado nele, portanto é de extrema importância as pessoas descobrirem o real significado do trabalho em suas vidas.

\subsubsection{Teorias sobre motivação}

Por ser tratar de um assunto complexo, surgiram diferentes teorias a respeito da motivação para sua explicação, a saber: a hierarquia de necessidades de Maslow, a Teoria X e a Teoria Y de McGregor, a Teoria dos Fatores Higiênicos de Herzberg e o Modelo Contingencial de Vroom.

\section{A hierarquia das necessidades de Maslow}

Conforme o psicólogo Abraham Maslow (1987 apud GIL, 2014, p. 205), as necessidades humanas expõem níveis diferentes de força. Diante desse fato foi estabelecido uma hierarquia de necessidades divididas em cinco grupos: fisiológicas (necessidades básicas como a alimentação, abrigo, vestimenta), de segurança (isenção de perigos e de privação das necessidades básicas), sociais (necessidade de relacionar-se com outros indivíduos), de estima (reconhecimento pelos outros e amor-próprio) e de autorrealização (atingir o máximo do potencial individual).

Gil (2014, p. 206) ressalta a importância da Teoria de Maslow em virtude de as pessoas não necessitarem, apenas, de recompensas financeiras, mas também de respeito e consideração de outros indivíduos.

Teoria X e a Teoria Y de McGregor

O psicólogo Douglas McGregor (1960 apud GIL, 2014, p. 206) definiu dois tipos distintos de gerenciamento, que denominou de Teoria X e Teoria Y, em que os adeptos da Teoria $\mathrm{X}$ acreditavam que a maior parte das pessoas eram avessas ao trabalho e sua equipe funcionaria apenas pela disciplina e pela expectativa de possíveis recompensas; já os adeptos da Teoria Y julgam que as pessoas consideram o trabalho como motivo de satisfação e que são dedicadas para a obtenção dos melhores resultados.

\section{A teoria dos fatores higiênicos e motivadores de}

\section{Herzberg}

Frederick Herzberg (1975 apud GIL, 2014, p. 207) considerou os fatores conhecidos como higiênicos e motivadores oferecendo uma importante contribuição aos estudos sobre a motivação. Os fatores higiênicos são: salários e benefícios, condições de trabalho, política da empresa, status, segurança no trabalho e supervisão (grau de controle que o colaborador tem sobre o seu trabalho). Fatores motivadores: responsabilidade, reconhecimento, desafios, realização e crescimento.

De acordo com Gil (2014, p. 208), a Teoria de Herzberg aponta que os fatores motivadores devem ser promovidos pelos gerentes para manter sua equipe motivada, porém a manutenção de tais fatores dependeria da satisfação no trabalho e do envolvimento de cada colaborador, onde os gerentes devem enriquecer o trabalho com o aumento das responsabilidades e desafios, sem desconsiderar os fatores higiênicos pois:

se é verdade que aumentar os salários não necessariamente leva as pessoas a trabalhar com mais afinco, pode, no entanto, deixá-las satisfeitas o bastante para que outros fatores possam motivá-las. Por outro lado, se o salário ou as condições de trabalho causam insatisfação, as pessoas tornam-se desmotivadas, e nenhum outro elemento será capaz de motivá-las (HERBERG, 1975 apud GIL, 2014, p. 206)

Modelo contingencial de Vroom

Vroom (1964 apud CHIAVENATO, 2005, p. 220) 
salienta que a motivação em uma empresa é função de três fatores determinantes:

- Expectativas: força do desejo de alcançar os objetivos individuais;

- Recompensas: relação percebida entre produtividade e o alcance dos objetivos individuais;

- Relações entre expectativas e recompensas: capacidade percebida de influenciar o seu próprio nível de produtividade.

\subsection{Discussões teóricas entre o clima organizacio- nal e a motivação em organizações}

Segundo Moura (2013), toda a organização tem a sua cultura, formada com base nos valores, crenças, costumes, tradições etc. Nesse processo, o fator humano é a peça-chave para o sucesso organizacional e os fatores como estress, motivação, liderança, estão intimamente associados ao clima organizacional bem como à sua satisfação das necessidades pessoais. Diante desse contexto, o ambiente da organização apresenta certas propriedades que podem influenciar a motivação para determinados comportamentos.

Conforme Garcia (2011), em uma organização onde os colaboradores estejam motivados, dificilmente se tem um clima organizacional insatisfatório, pois, quando as pessoas estão felizes, o clima é favorável e harmônico dentro da empresa, permitindo a satisfação das necessidades do indivíduo, o que afeta de forma positiva as suas atividades e a partir disso, o colaborador sente-se motivado a contribuir com a organização para a mesma atingir seus objetivos. O autor complementa com a percepção por meio das pesquisas feitas, que, dentre os fatores que mais influenciam a motivação dos colaboradores na instituição estudada, estão o ambiente de trabalho, o trabalho em si, o relacionamento interpessoal e o salário.

Brunelli (2008) constatou que os fatores higiênicos influenciam a motivação dos colaboradores da empresa estudada mais do que os fatores motivacionais. Os resultados obtidos na pesquisa apontam que os fatores motivadores "responsabilidade, autonomia, participar das decisões e realização pessoal e profissional" e os fatores higiênicos "relacionamento com a chefia, relacionamento interpessoal e estabilidade" são os que mais influenciam os servidores, sendo os que mais contribuem para a satisfação e motivação no trabalho.

De acordo com Oliveira (2008), é, com base na realização da pesquisa de clima organizacional, em conjunto com o delineamento do perfil motivacional, que se pode ter a realimentação em relação às políticas de recursos humanos praticadas na organização para que se possa, em um segundo momento, fazer intervenções estratégicas que alinhem as necessidades de ambos $\nabla$ colaboradores e organização. Com o estudo realizado, pode-se inferir que o clima organizacional influencia a motivação dos funcionários, tendo em vista que o único fator do clima organizacional a ter uma percepção negativa dos colaboradores na empresa estudada foi o fator "Política de remuneração".

\section{Metodologia}

Este capítulo trata da metodologia empregada nesta pesquisa, cuja finalidade é proporcionar a compreensão da influência do clima organizacional no aspecto motivacional dos colaboradores da organização estudada. A seção 3.1 serão apresentados os métodos de pesquisa e os procedimentos técnicos de coleta de dados.

\subsection{Descrição do método de pesquisa}

O projeto tem como propósito apresentar soluções para problemas já diagnosticados. Foi empregado o método descritivo, que segundo Best (1972 apud MARCONI; LAKATOS, 2010, p. 6) "Delineia o que é - aborda também quatro aspectos: descrição, registro, análise e interpretação de fenômenos atuais, objetivando o seu funcionamento no presente". Para Hymann (1967 apud MARCONI; LAKATOS, 2010, p. 6), a pesquisa descritiva é a simples descrição de um fenômeno. Já para Selltiz et al (1965, p. 61) os estudos descritivos "descrevem um fenômeno ou situação, mediante um estudo realizado em determinado espaço-tempo". Ainda sobre a conceituação de pesquisa descrita, outros autores contribuem:

Nesse tipo de pesquisa não há a interferência do pesquisador, isto é, ele descreve o objeto de pesquisa. Procura descobrir a frequência com que um fenômeno ocorre, sua natureza, características, causa, relações e conexões com outros fenômenos. A pesquisa descritiva engloba dois tipos: a pesquisa documental e/ou bibliográfica e a pesquisa de campo (BARROS; LEHFELD, 2000, p.).

\subsection{Descrição das técnicas de coleta de dados}

Para atender o método anteriormente proposto, 
foram empregados como procedimentos de coleta de dados a pesquisa bibliográfica e a pesquisa de campo.

De acordo com Marconi e Lakatos (2010, p. 57), a pesquisa bibliográfica "abrange toda bibliografia já tornada pública em relação ao tema de estudo" e "sua finalidade é colocar o pesquisador em contato direto com tudo o que foi escrito, dito ou filmado sobre determinado assunto". Conforme Manzo (1971 apud MARCONI; LAKATOS, 2010, p. 57) “a bibliografia pertinente oferece meios para definir, resolver não somente problemas já conhecidos, como também explorar novas áreas onde os problemas não se cristalizavam suficientemente". Para se realizar uma pesquisa bibliográfica, é fundamental que o pesquisador faça um levantamento dos temas e tipos de abordagens já trabalhadas por outros estudiosos, assimilando os conceitos e explorando os aspectos já publicados (BARROS; LEHFELD, 2000).

Marconi e Lakatos (2010, p. 69) sustentam a seguinte afirmação para pesquisa de campo: "é aquela utilizada com o objetivo de conseguir informações e/ ou conhecimentos acerca de um problema para o qual se procura uma resposta, ou de uma hipótese que se queira comprovar, ou, ainda descobrir novos fenômenos ou as relações entre eles.”

Trujillo (1982, p. 229) acredita que a pesquisa de campo ainda "não deve ser confundida com a simples coleta de dados (esta última corresponde à segunda fase de qualquer pesquisa); é algo mais que isso, pois exige contar com controles adequados e com objetivos preestabelecidos que discriminam suficientemente o que deve ser coletado". O investigador na pesquisa de campo assume o papel de observador e explorador, coletando diretamente os dados no local (campo) em que se deram ou surgiram os fenômenos (BARROS; LEHFELD, 2000).

\subsection{Descrição do público-alvo}

O público-alvo são os colaboradores de um dos departamentos de uma Instituição Federal Pública de ensino superior, com sede em Brasília, Distrito Federal. O quadro de pessoal no setor é composto por 16 colaborados. Foi realizado um estudo de caso na organização. Segundo Barros e Lehfeld (2000, p. 95) o estudo de caso refere-se à análise minuciosa de um caso individual. Para Gil (2010, p. 57), “o estudo de caso é caracterizado pelo estudo profundo e exaustivo de um ou de poucos objetos, de maneira a permitir o seu conhecimento amplo e detalhado, tarefa praticamente impossível mediante os outros tipos de delineamentos considerados". Pode-se definir ainda estudo de caso como uma pesquisa empírica que investiga um fenômeno atual dentro do seu contexto de realidade, quando as fronteiras entre o fenômeno e o contexto não são claramente definidas e no qual são utilizadas várias fontes de evidência (YIN, 2005 apud GIL, 2010, p. 58).

\subsection{Delineamento da pesquisa de campo}

Foi realizado um censo no setor estudado, pois o número de colaboradores no quadro é menor que 30 pessoas, totalizando 16 funcionários. Todos os colaboradores participaram da pesquisa. Como instrumento de coleta de dados, foi utilizado o questionário, que, segundo Barros e Lehfeld (2000, p. 91), “possibilita ao pesquisador abranger um maior número de pessoas e informações em curto espaço de tempo do que outras técnicas de pesquisa”. O modelo de questionário aplicado foi o estruturado, com perguntas fechadas sobre fatores qualitativos do ambiente de trabalho, com respostas em escala de Likert, que de acordo com Chisnall (1973) além de serem confiáveis, são mais simples de construir e permitem obter informações sobre o nível dos sentimentos dos respondentes, o que dá mais liberdade a eles.

\section{Análise}

O objetivo deste capítulo é a realização da análise dos dados obtidos mediante a aplicação do questionário no setor da organização estudada, para o correto diagnóstico do clima organizacional e sua interferência na motivação dos colaboradores.

\subsection{Descrição do estudo de caso}

A organização que foi objeto do estudo é uma Instituição Federal Pública de Ensino Superior, de pesquisa e estudo, divulgação científica, técnica e cultural, com sede em Brasília, Distrito Federal. O departamento estudado na organização tem como função principal executar a autuação de documentos de todas as unidades da instituição de ensino, realizando as atividades de receber, registrar, protocolar, autuar, tramitar, distribuir e expedir os processos, documentos e correspondências. Foi realizada a pesquisa com foco no clima organizacional do setor para a identificação de sua possível relação com a motivação dos funcionários. 


\subsection{Análise do estudo de caso}

Esta sessão apresenta por meio de gráficos ilustrativos os resultados dos dados apurados sobre o perfil dos colaboradores entrevistados (sexo, idade, escolaridade), os fatores escolhidos para o diagnóstico do clima na organização (clareza organizacional, reconhecimento, condições físicas e materiais, percepção do clima, trabalho em equipe, relacionamento interpessoal, conflitos, rotatividade, produtividade, liderança, avaliação de desempenho) e os principais elementos que geraram motivação nos funcionários segundo os mesmos.

O Gráfico 1 revela que a maioria dos funcionários do setor, isto é, $56 \%$ são representados pelo gênero feminino.

Gráfico 1 - Sexo

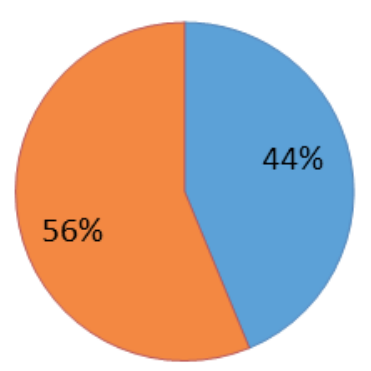

Masculino $\square$ Feminino

Fonte: Dos autores.

No Gráfico 2, observa-se que a maioria dos colaboradores, 69\%, está na faixa etária de 18 a 30 anos, o que revela um perfil predominantemente jovem no setor.

Gráfico 2 - Idade

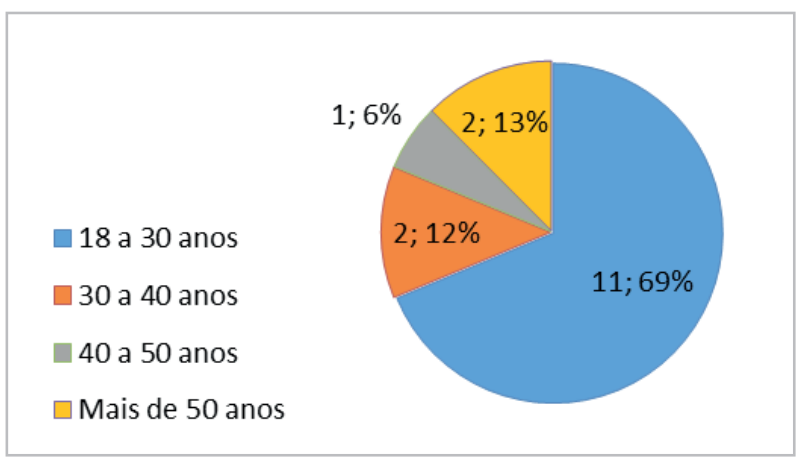

Fonte: Dos autores.

O Gráfico 3 mostra que a maioria dos colaboradores do setor possui ensino superior incompleto, 37\% dos entrevistados, seguido de um empate entre o ensino superior completo, ensino médio completo e ensino médio incompleto com 19\% respectivamente. A escolaridade da maioria se justifica pelo fato de grande parte dos colabo- radores estar na faixa entre 18 e 30 anos, grande parte em processo de formação no nível superior.

Gráfico 3 - Escolaridade

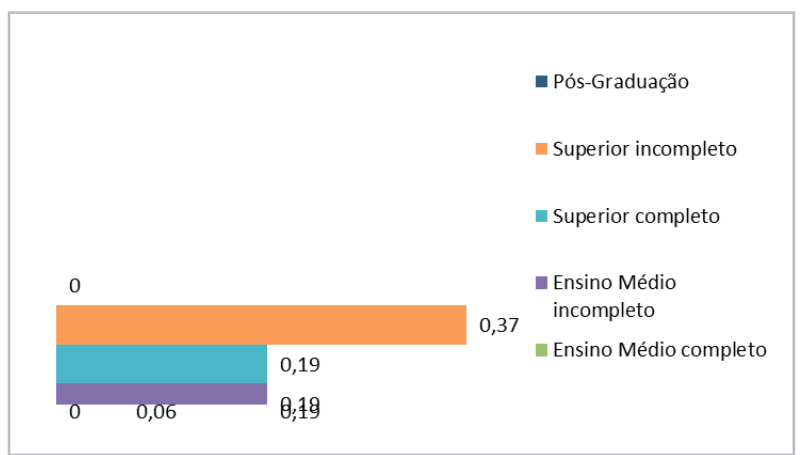

Fonte: Dos autores.

No Gráfico 4, tem-se o primeiro aspecto relacionado ao clima da organização, relativo à clareza e objetividade em que os colaboradores são orientados em relação ao seu trabalho, a maioria, 56\%, respondeu que as orientações são sempre claras e objetivas. Isso demonstra que o setor possui clareza organizacional, uma das sete variáveis-chave do clima organizacional proposta por Litwin e Stringer (apud GRAÇA, 1999).

Grafico 4 - Clareza e objetividade para orientar os colaboradores sobre o trabalho

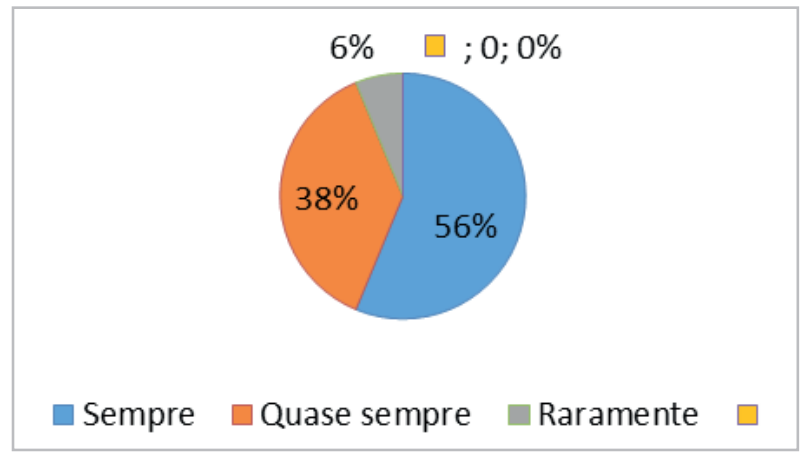

Fonte: Dos autores.

O Gráfico 5 traz o questionamento de como os colaboradores se sentem em relação ao reconhecimento por parte da organização dos trabalhos bem realizados por eles, sendo que $44 \%$ das respostas foram que quase sempre a instituição reconhece o bom trabalho desenvolvido pelos funcionários. $\mathrm{O}$ reconhecimento integra a necessidade de estima proposta na Teoria Motivacional da Hierarquia das necessidades de Abram Maslow, em que Gil (2014) ressalta a importância da teoria de Maslow em virtude das pessoas não necessitarem apenas de recompensas financeiras, mas também de respeito e consideração de outros indivíduos. O reconhecimento é um elemento 
importante para a motivação, e no setor esse quesito foi bem avaliado.

Gráfico 5 - Reconhecimento da instituição perante os trabalhos realizados pelos colaboradores

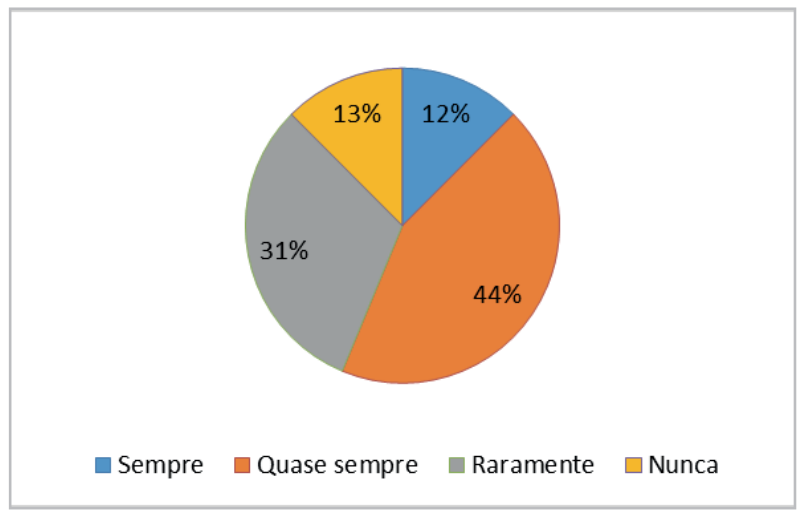

Fonte: Dos autores.

Evidencia-se, no Gráfico 6, que grande parte dos funcionários está satisfeita com as condições físicas e materiais do ambiente de trabalho, $44 \%$ das respostas demonstraram que quase sempre a organização oferece as condições supracitadas e $37 \%$ consideraram que sempre há tais condições. Um local de trabalho com condições físicas e materiais adequadas é necessário para a qualidade do ambiente e no caso do setor os resultados estão positivos.

Gráfico 6 - Condições físicas e materiais satisfatórias para execução do trabalho suas implicações, para que seu entendimento fosse efetivo. Como dito por Chiavenato (2005), o clima compõe a qualidade do ambiente da empresa, sendo percebido pelos colaboradores da organização e influenciando diretamente o comportamento destes. Diante do exposto, pode-se afirmar que o setor possui clima positivo.

Gráfico 7 - Percepção do clima no ambiente de trabalho

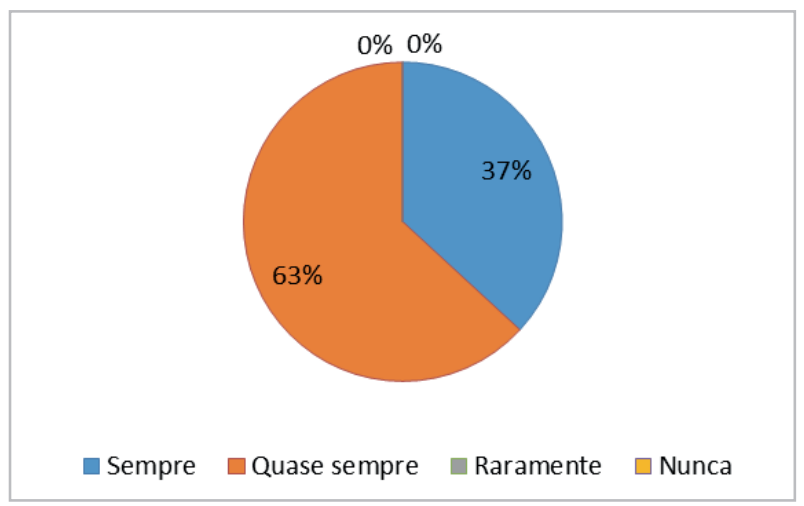

Fonte: Dos autores.

Os resultados demonstrados no Gráfico 8, relacionados ao incentivo que a instituição enseja nos colaboradores para o trabalho em equipe, são positivos, 37\% acreditam que quase sempre há o incentivo e $31 \%$ admitiram que sempre ocorre incentivo para se trabalhar em equipe. Gráfico 8 - Incentivo ao trabalho em equipe

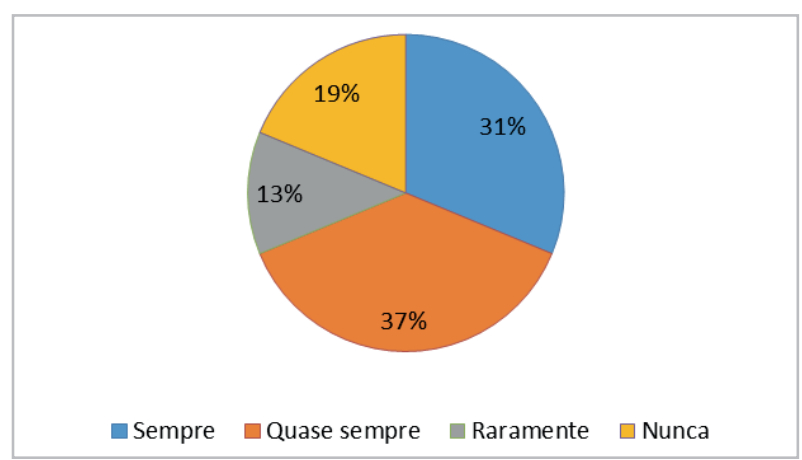

Fonte: Dos autores.

O Gráfico 9 revela um fator muito importante na constituição de um clima organizacional benéfico, o relacionamento entre os colaboradores. A maioria, 56\%, concordou que o relacionamento com os colegas é muito bom, e apenas $6 \%$, avaliou como razoável. Podemos identificar a variável-chave do clima organizacional calor humano e apoio de Litwin e Stringer (apud GRAÇA, 1999), que, conforme os autores, é o sentimento de que a amizade é uma norma valorizada na organização e que boas relações prevalecem. Isso torna o ambiente de trabalho mais harmônico. 
Gráfico 9 - Relacionamento entre colegas

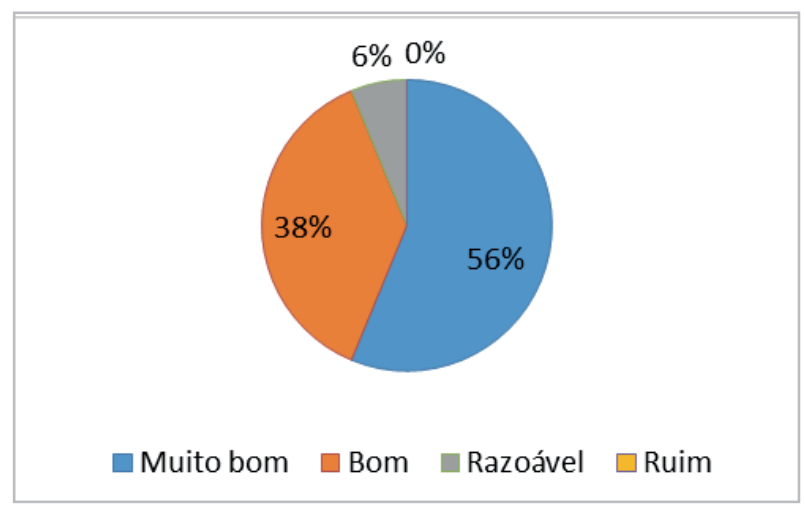

Fonte: Dos autores.

No Gráfico 10, visualiza-se que 44\% dos respondentes desconhecem conflitos entre os funcionários, seguido de $31 \%$ que julgaram não existir conflitos na equipe. Conflitos interpessoais e interdepartamentais é um dos indicadores propostos por Luz (2005), que considera tais conflitos a forma mais aparente do clima de uma empresa. Como a maioria dos colaboradores confirmou que desconhecem ou que os conflitos não existem, salvo uma parcela de $25 \%$ que caracterizou a resposta como parcialmente, pode-se afirmar que o clima do setor é propiciamente benéfico.

Gráfico 10 - Conflitos entre colaboradores

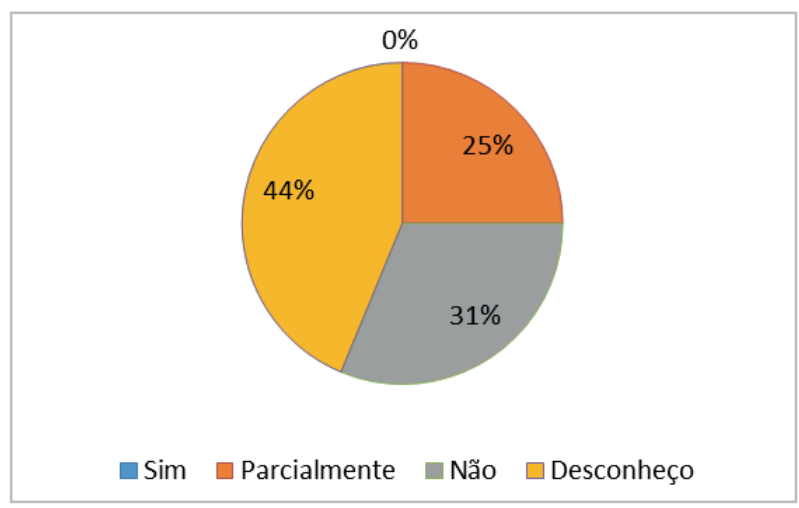

Fonte: Dos autores.

O Gráfico 11 mostra de acordo com a opinião dos colaboradores do setor o índice de rotatividade, no caso, $56 \%$ dos entrevistados julgaram o índice moderado. Conforme dito por Luz (2005), o turnover ou rotatividade de pessoal é outro indicador do clima de uma organização, quando elevado demonstra a falta de comprometimento e insatisfação dos funcionários. No caso da organização estudada, de acordo com o entendimento da maioria dos colaboradores, o índice em questão foi considerado moderado, um resultado que pode-se avaliar como positivo.
Gráfico 11 - Índice de rotatividade dos funcionários no setor

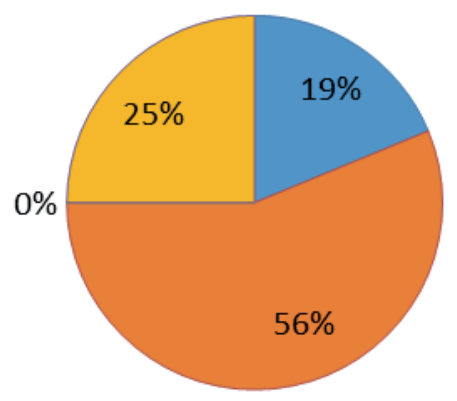

$\square$ Alto $\square$ Moderado $\square$ Baixo $\square$ Desconheço

Fonte: Dos autores.

O Gráfico 12 ilustra, de acordo com a percepção dos entrevistados, que $50 \%$ consideraram sempre produtivo o trabalho desenvolvido e apenas 6\% raramente produtivo. Robbins (2002) menciona que a produtividade está relacionada à satisfação no trabalho e ao desempenho dos funcionários, as “empresas felizes” são mais produtivas, pois funcionários satisfeitos tendem a ser mais eficazes. Logo, entende-se que existe satisfação por parte dos funcionários no setor estudado e isso influencia no desempenho dos mesmos.

Gráfico 12 - Produtividade do trabalho desenvolvido

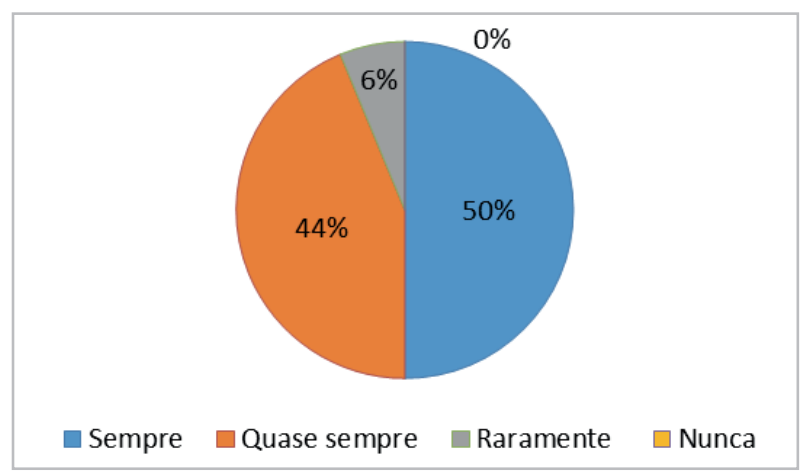

Fonte: Dos autores.

O Gráfico 13 apresenta os resultados referentes à pergunta sobre o relacionamento com o líder, os resultados se mostraram extremamente positivos, onde $50 \%$ consideraram muito bom, $44 \%$ bom e apenas $6 \%$ razoável. A liderança é outra variável-chave definida por Litwin e Stringer (apud GRAÇA, 1999) para compor as dimensões do clima em uma empresa, e no caso em estudo, a liderança foi bem avaliada e é satisfatória. 
Gráfico 13 - Relacionamento com o líder

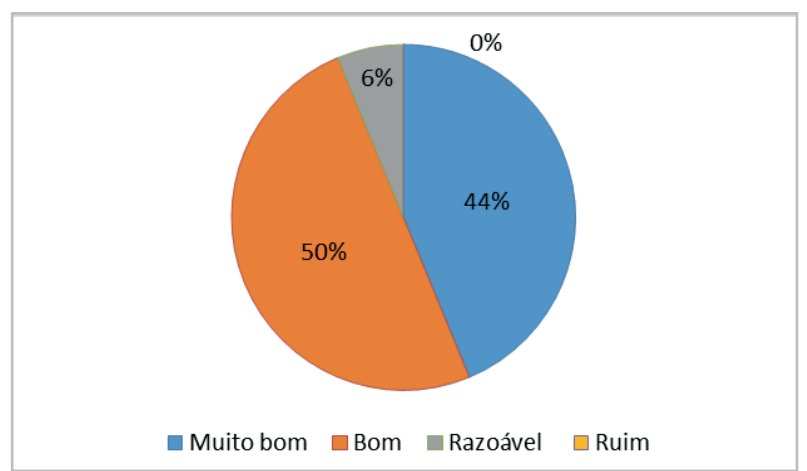

No Gráfico 14, tem-se dados ainda relativos à liderança exercida, por se tratar de um aspecto muito importante do clima organizacional. A pergunta foi formulada levando em consideração outro elemento relacionado ao tema da pesquisa, a motivação. Quando perguntados se o superior hierárquico incentiva à motivação dos colaboradores, como resultado, foi constatado que 38\% dos motivação, $31 \%$ que quase sempre e apenas $6 \%$ que nunca há tal incentivo.

Gráfico 14 - Incentivos da liderança em relação a motivação dos colaboradores

da dentro das próprias pessoas e pode ser amplamente influenciada por fontes externas ao indivíduo ou pelo seu próprio trabalho na empresa, em que o líder deve conhecer o potencial interno de motivação de cada pessoa e deve saber extrai do ambiente de trabalho as condições externas para elevar a satisfação profissional. Por tanto, no caso de o setor, os liderados acreditam que o líder consegue incentivar a motivação destes .

O Gráfico 15 revela o grau de satisfação dos colaboradores com a remuneração e os benefícios oferecidos. Foi constatado que $44 \%$ dos entrevistados estão pouco satisfeitos. Houve empate com colaboradores satisfeitos
Fonte: Dos autores. entrevistados avaliaram que o líder sempre incentiva a

ger (apud GRAÇA, 1999) definiram as recompensas como uma das dimensões do clima na empresa, sendo o grau em que os membros se sentem recompensados pelo trabalho. Assim como na pesquisa de Oliveira (2008), a remuneração apareceu de forma mais negativa do que positiva na percepção dos colaboradores, dessa forma, conclui-se que esse fator poderia ser melhorado, por ser tratar de um elemento considerado relevante no clima de uma organização.

Gráfico 15 - Grau de satisfação com a remuneração e benefícios

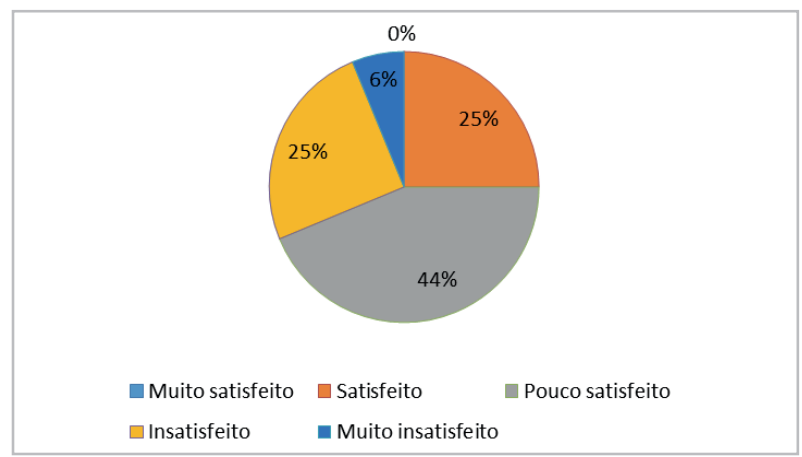

Fonte: Dos autores.

O Gráfico 16 é relativo a como os colaboradores se sentem no que se concerne à avaliação de desempenho e feedback recebidos em relação ao trabalho desenvolvido. Os resultados apontam que 56\% se consideram satisfeitos e $12 \%$ muito satisfeitos. A avaliação de desempenho é outro indicador do clima organizacional exposto por Luz (2005), pois as informações sobre o baixo desempenho dos funcionários revelam o seu estado de ânimo em relação a empresa. No caso do setor analisado, a maioria se considerou bem avaliado, o que implica que os funcionários têm um bom desempenho em suas atividades e o estado de ânimo da maioria está elevado, contribuindo para um ambiente de trabalho favorável.

Gráfico 16 - Avaliação de desempenho e feedback e insatisfeitos com $25 \%$ respectivamente. Litwin e Strin-

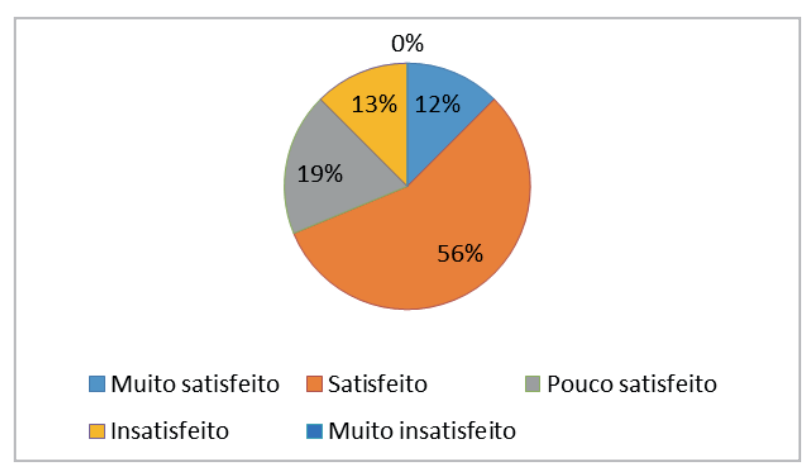

Fonte: Dos autores.

O Gráfico 17 traz os resultados sobre os principais motivos pelos quais os colaboradores trabalhavam na or- 
ganização, o que mais influenciava a motivação. Os resultados apontaram 5 razões principais dentre as 10 possíveis sugeridas, além do espaço em aberto para outras e o salário apareceu em primeiro lugar com $34 \%$, seguido do ambiente de trabalho com $25 \%$.

Gráfico 17 - Principais motivos pelos quais os colaboradores trabalham na organização-motivações

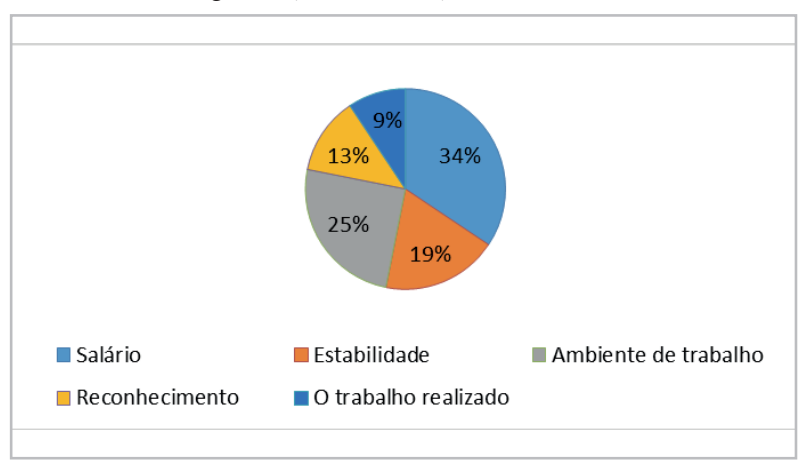

Fonte: Dos autores.

Tais achados correspondem com alguns resultados obtidos na pesquisa realizada por Garcia (2011), que apresentou, também, os elementos ambiente de trabalho, o trabalho em si e o salário como os fatores que influenciavam os colaboradores na empresa que foi analisada no estudo, além do fator relacionamento interpessoal, esse, que mesmo sendo proposto no questionário da presente pesquisa, não foi escolhido pelos entrevistados.

Por meio dessa análise, pode-se concluir que o clima organizacional do setor analisado é favorável, como foi cunhado no Gráfico 7 , relativo à percepção do clima no setor pelos colaboradores. Os demais gráficos apresentaram resultados também positivos em relação à clareza organizacional, reconhecimento, condições físicas e materiais, trabalho em equipe, relacionamento interpessoal, conflitos, rotatividade, produtividade, liderança e avaliação de desempenho. $\mathrm{O}$ único resultado negativo foi relativo à remuneração e por ter sido escolhido pelos colaboradores no questionário como o principal elemento que os motiva, deve-se dar uma atenção em especial a esse fator. O Gráfico 17 mostrou o ambiente de trabalho como segundo maior fator que influência a motivação dos funcionários do departamento e se constatou que o ambiente de trabalho do setor possui clima benéfico e satisfatório.

Pelo fato de o clima no setor de trabalho ser apropriado, há um aumento na satisfação e consequentemente na motivação. Como afirmado por Chiavenato (2005), o clima organizacional influencia a motivação, o desempenho humano e a satisfação no trabalho. Na pesquisa apresentada por Moura (2013), foi identificado que o fa- tor humano é a peça chave para o sucesso organizacional e, os fatores como o estresse, motivação, liderança, estão intimamente associados ao clima organizacional bem como à satisfação das necessidades pessoais. Logo, o ambiente da organização apresenta certas propriedades que podem influenciar a motivação para determinados comportamentos.

Assim, comprova-se neste estudo, com base nos resultados demonstrados nessa relação, que o clima organizacional possui fatores que afetam a satisfação das pessoas inseridas no ambiente de trabalho, interferindo, assim, em sua motivação.

\section{Conclusão}

A importância capital humano nas organizações tem sido reconhecida ao longo dos anos em uma escala crescente. Contudo, esse capital tão precioso necessita estar inserido em um ambiente organizacional saudável, para, assim, atingir a produtividade e efetividade que todas as organizações almejam. Diante dessa conjectura, o objetivo geral do estudo foi pesquisar a influência do clima organizacional na motivação dos colaboradores do setor da organização analisada.

Para a realização e desenvolvimento do presente estudo, foi empregado o método descritivo e como técnica de coleta de dados, foram utilizados o levantamento bibliográfico e a pesquisa de campo em um dos setores de uma Instituição Pública Federal de Ensino Superior do Distrito Federal.

A análise da pesquisa foi principalmente fundamentada segundo as variáveis-chave de Litwin e Stringer (apud GRAÇA, 1999) e os indicadores do clima organizacional de Luz (2005). Contou, também, com a contribuição da Teoria Motivacional da Hierarquia das Necessidades de Abram Maslow (apud GIL, 2014), com as percepções de Chiavenato (2005) e Robbins (2002), e os achados das pesquisas de Garcia (2011), Oliveira (2008) e Moura (2013) como forma de comparação.

Em face da conceituação teórica e da análise realizada com base nos gráficos apresentados no diagnóstico, depreende-se que o clima organizacional tem elementos que são capazes de influenciar a motivação das pessoas. Neste estudo, o salário foi escolhido pelos respondentes da pesquisa de campo como um dos principais fatores que os motiva, seguido do ambiente de trabalho. Em relação à remuneração, os gestores da instituição devem ficar 
atentos à insatisfação que esses vencimentos causam aos funcionários, a fim de evitar possíveis problemas futuros.

Não obstante, a pesquisa constatou que o ambiente é satisfatório e possui clima organizacional benéfico, em que a maioria dos fatores e indicadores que mensuraram o grau de qualidade do clima da organização objeto de estudo apresentaram resultados positivos. Perante esses fatos, há uma elevação na satisfação das pessoas do setor, influenciando a motivação das mesmas. As duas variáveis deste estudo (clima organizacional e motivação) se mostraram relacionadas. Ressalta-se, mais uma vez, a escolha dos colaboradores em determinar o ambiente de trabalho como um dos principais fatores que os motivam.

Os estudos sobre a motivação humana merecem total atenção, por sua natureza intrínseca e extrínseca, mesmo com sua frequente abordagem em diversas pesquisas científicas, pois o tema ainda gera discussões e merece aprofundamento contínuo. O clima organizacional, nos últimos anos, obteve uma crescente visualização por parte dos gestores de grandes organizações, e é cada vez mais comum a preocupação com sua qualidade. Sem dúvida é um assunto que pode ainda ser amplamente difundido. Uma das dificuldades da pesquisa foi encontrar livros específicos sobre a temática do clima organizacional. Mesmo sendo citado em diversas obras literárias, sua menção é feita de forma ainda muito genérica na maioria destas publicações teóricas. Quanto mais publicações e aprofundamento do estudo sobre, melhor será para as pesquisas futuras.

\section{Referências}

BARROS, Aidil de Jesus S. P.; LEHFELD, Neide Aparecida de S. Fundamentos de metodologia científica: um guia para a iniciação científica. 2. ed. São Paulo: Makron Books, 2000.

BERGAMINI, Cecília Whitaker. Psicologia aplicada à administração de empresas: psicologia do comportamento organizacional. 4. ed. São Paulo: Atlas, 2011.

BRUNELLI, Maria da Graça M. Motivação no serviço público. 2008. 89 f. Dissertação (MBA em Gestão Pública) Instituto Brasileiro de Gestão de Negócios, Porto Alegre, 2008.
CHIAVENATO, Idalberto. Gerenciando com as pessoas: transformando o executivo em um excelente gestor de pessoas: um guia para o executivo aprender a lidar com sua equipe de trabalho. Rio de Janeiro: Elsevier, 2005.

CHISNALL, Peter. Marketing research: analysis and measurement. London: McGraw-Hill, 1973.

GARCIA, Elisandra Manuela T. Motivação e clima organizacional: o caso do Centro de Formação Profissional de Pedra Badejo. 2011. 85 f. Monografia (Licenciatura em Relações Públicas e Secretariado Executivo) - Universidade de Cabo Verde, Calheta, 2011.

GIL, Antônio Carlos. Gestão de pessoas: enfoque nos papéis profissionais. São Paulo: Atlas, 2014.

GIL, Antônio Carlos. Métodos e técnicas de pesquisa social. 6. ed. São Paulo: Atlas, 2010.

GRAÇA, Hélio. Clima organizacional: uma abordagem vivencial. Brasília: FUNADESP, 1999.

HOLLENBECK, John R.; WAGNER III, John A. Comportamento organizacional: criando vantagem competitiva. São Paulo: Saraiva, 2004.

LUZ, Ricardo. Gestão do clima organizacional. Rio de Janeiro: Qualitymark, 2005.

MARCONI, Marina de Andrade; LAKATOS, Eva Maria. Técnicas de pesquisa: planejamento e execução de pesquisas, amostragens e técnicas de pesquisa, elaboração, análise e interpretação de dados. 7. ed. São Paulo: Atlas, 2010.

MOURA, Manuel Antunes V. Clima organizacional e motivação dos funcionários da Alfândega da Praia. 2013. 97 f. Monografia (Licenciatura em Administração Pública e Autárquica) - Universidade Jean Piaget de Cabo Verde, Cidade da Praia, 2013.

OLIVEIRA, Anderson Muniz. A influência do clima organizacional na motivação dos servidores da Fundação Alfredo da Matta. 2008. 77 f. Dissertação (Mestrado) - Escola Brasileira de Administração Pública e de Empresas, Fundação Getúlio Vargas, Rio de Janeiro, 2008.

ROBBINS, Stephen P. Comportamento organizacional. 9. ed. São Paulo: Prentice Hall, 2002. 
SELLTIZ, C. et al. Métodos de pesquisa nas relações sociais. São Paulo: Herder, 1965.

TRUJILlO, Alfonso Ferrari. Metodologia da pesquisa científica. Rio de Janeiro: McGraw-Hill do Brasil, 1982.

VERGARA, Sylvia Constant. Gestão de pessoas. 10. ed. São Paulo, 2011. 